\title{
Microplastics in the Ocean
}

\author{
Won Joon Shim ${ }^{1,2} \cdot$ Richard C. Thomposon ${ }^{3}$
}

Received: 30 July 2015/ Accepted: 6 August 2015/Published online: 2 September 2015

(C) Springer Science+Business Media New York 2015

\begin{abstract}
Since their ubiquity in the ocean and marine organisms was first revealed, global concern about microplastics has grown considerably. The North Pacific Ocean and the adjacent marginal seas have high levels of microplastic contamination compared with the global average. This special issue on microplastics was organized by the North Pacific Marine Science Organization to share information on microplastic pollution in the North Pacific region. The special issue highlights high levels of contamination in the North Pacific both on shorelines and at the sea surface. Particularly high levels of contamination were reported on the western and southern coasts of Korea. Sources, including sewage discharge, aquaculture, and shipyards, were implicated. With the direction and energy of surface winds and currents have an important influence on shoreline patterns of distribution. The special issue also demonstrates potential for ingestion of microplastic by small planktonic organisms at the base of the food chain. A wide range of chemicals are associated with plastic debris and concerns are expressed about the potential for these chemicals to transfer to biota upon ingestion. As an
\end{abstract}

This article represents an introduction to a Special Issue on

'Microplastics' in Archives on Environmental Contamination and Toxicology.

Won Joon Shim

wjshim@kiost.ac

1 Oil and POPs Research Group, Korea Institute of Ocean Science and Technology, Geoje 656-834, South Korea

2 Department of Marine Environmental Science, University of Science and Technology, Daejeon 305-320, South Korea

3 Marine Biology and Ecology Research Centre (MBERC), School of Marine Science and Engineering, Plymouth University, Drake Circus, Plymouth, Devon PL4 8AA, UK introduction to the topic, this paper provides a brief background on microplastic contamination, highlights some key research gaps, and summarizes findings from the articles published in this issue.

\section{Background}

Marine pollution by plastic litter has been a major global environmental issue in recent decades, and global concern over the problems resulting from end-of-life plastic have grown rapidly since the presence of microscopic plastic particles in the ocean and an increasing trend in their abundance were documented in the early 2000s (Thompson et al. 2004, but see also earlier work (Carpenter et al. 1972; Colton et al. 1974; Ryan and Moloney 1990)). Small fragments of plastic litter in the environment present different challenges to larger items, which has been widely documented since the 1960s. As large items fragment into microplastics, the abundance of litter increases, and this effectively increases their availability (encounter rate) to wildlife. In addition, decreasing particle size increases the range of organisms that can ingest the debris (Law and Thompson 2014). Hence, smaller plastics become more bioavailable (or ingestible) particularly to small organisms. In addition, this increased surface area increases the potential for leaching or desorption of additive or adsorbed chemicals to an organism upon ingestion. However, because of their size detecting the presence of microplastics and adverse biological effects, if any, becomes considerably more challenging. In addition, the persistence of plastic particles in the environment can increase because small plastic particles would be extremely difficult to remove from the environment manually. 
Engineered micro-sized plastics (primary microplastics), such as cosmetics scrubbers and abrasive beads used in sandblasting, can be introduced directly into aquatic environments by discharge after use or in accidental spills. Microplastics can be generated in the environment via the fragmentation of larger plastic items and litter (secondary microplastics). Global annual plastic production has increased drastically, reaching 299 million tons in 2014 (PlasticEurope 2015). An estimated 4.8-12.7 million tons of plastics entered the ocean from land-based sources in 192 coastal countries in 2010 (Jambeck et al. 2015). If ocean-based sources, such as fisheries and shipping activities, are included, the total input of plastics to the oceans is considerably higher. One estimate for the minimum total quantity of floating plastic litter $(>0.33 \mathrm{~mm}$ in size $)$ in the oceans is 0.27 tons (5.25 trillion particles), with microplastics (0.33-4.75 $\mathrm{mm}$ in size) accounting for $92 \%$ by number of plastic particles and $13 \%$ by weight (Eriksen et al. 2014). However, these data do not include plastics on the seabed (Woodall et al. 2014) and beaches (Browne et al. 2010) or those of particle size $0.001-0.33 \mathrm{~mm}$, which account for the majority of the total abundance of microplastics (Song et al. 2014).

Microplastics have been observed on the shore, sea surface, and seabed from the coast to the open ocean, including the Arctic (Obbard et al. 2014) and Antarctic Oceans (Law and Thompson 2014). They are ingested by diverse biota, such as invertebrates, turtles, fish, birds, and marine mammals (Wright et al. 2013b) and approximately $10 \%$ of the reports of encounters between marine litter and species now relate to encounters with microplastic debris (Gall and Thompson 2015). After ingestion, microplastics could have adverse physical (Wright et al. 2013a, b) and chemical (Browne et al. 2013; Rochman et al. 2013) effects on these organisms due to their small size and associated toxicants (Lithner et al. 2011; Lee et al. 2013), and there are concerns that they could affect the safety of seafood (Seltenrich 2015).

\section{Research Gaps}

Since tiny plastic particles were first recorded in surface water and fish in the early 1970s (Carpenter and Smith 1972), little attention was paid to their presence until they were highlighted as "microplastics" in the early 2000s (Thompson et al. 2004). A number of recent review papers and reports have summarised current research gaps and priorities in detail (Thompson et al. 2009; Andrady 2011; Cole et al. 2011; Engler 2012; Syberg et al. 2015; GESAMP 2015; Eerkes-Medrano et al. 2015; Van Cauwenberghe et al. 2015). Although studies have examined the distribution, fate, ingestion, and effects of microplastics to fill knowledge gaps and the number of scientific publications has increased exponentially over the past decade (GESAMP 2015), more questions than answers remain. Among the many important topics, a key issue is to determine how harmful current and anticipated future levels of microplastic pollution in the coastal and open ocean actually are. This can only be achieved by considering the probability of encounter and the severity of any effects resulting from encounter in a risk assessment matrix. This needs to be considered for wildlife, natural habitats, and human health.

Such risk assessments require data on the exposure and effects of the various sizes, shapes, and polymer types of microplastics and their associated toxic chemicals on various marine organisms and humans. The factorial combination of these parameters requires vast datasets that need to be generated using harmonized or standardized experimental approaches. Furthermore, although research has examined the occurrence and distribution of microplastics in the environment and organisms, and their adverse biological effects studied in laboratories, considerable inconsistencies remain in the sampling and hence quantification of microplastics in the environment. Whereas for microplastics in sediments very small particles have been isolated (Hidalgo-Ruz et al. 2012), floating microplastics are typically monitored using a $>0.33-\mathrm{mm}$ neuston net and only a few studies have examined plastics of tens of $\mu \mathrm{m}$ in size due to the technical barriers in sampling and analysis. By contrast, the effects of microplastics have mostly been studied in plastic particles ranging in size from nanometers to tens of micrometers, and it has been suggested that these could be more likely to have detrimental effects on the biota. Consequently, it is currently very challenging if not impossible to compare field monitoring data with laboratory toxicity data. This could be resolved by studying the combined physical and chemical effects of microplastics by simulations of the natural environment. However, this requires the development of test materials including standardised microplastics of various known sizes, shapes, polymer types, and chemical additive. Nanoplastics have not been quantified in the environment but are likely to be present in considerably greater numbers than micro- and millimeter-sized plastics. Successful detection and quantification of nanoplastics in the environment could provide an entirely new perspective on the scale of microplastic pollution. In addition, few studies have examined the processes, rates, and conditions for generating secondary microplastics from diverse large plastic litter in the environment. Much remains unknown regarding the environmental consequences of microplastic pollution, and more detailed studies are required to assess the ecological and human health risks. 


\section{Papers Presented in this Special Issue}

This special issue on microplastics follows the session on marine plastic litter held by the North Pacific Marine Science Organization (PICES) in Yeosu, South Korea, October, 2014. The North Pacific Ocean and its marginal seas have the highest microplastic contamination levels in the world (Eriksen et al. 2014; Song et al. 2014; Cózar et al. 2015). Therefore, it is important to collect and share information on microplastic pollution in the North Pacific region among global scientific and policy audiences. Eleven papers, including this one, were selected for publication in this issue, focusing mainly on the occurrence and distribution of microplastics in surface water and on the seashore in Far-east Asia, and in zooplankton or sediment samples in the Northeast Pacific or North America. The highest levels of global seawater microplastic contamination, including micro-sized paint resin particles, were reported along the western (Chae et al. 2015) and southern (Song et al. 2015) coasts of Korea. High accumulation of microplastics in the sea-surface microlayer was found, and intensive monitoring in near shore waters combined with polymer composition profiles revealed varied input sources, such as sewage discharge, aquaculture farms, and shipyards (Chae et al. 2015; Song et al. 2015). The highest microplastic contamination in the world was recorded on sand beaches in Korea, and a significant relationship was found among the meso- (5-25 $\mathrm{mm}$ in size) and large micro-plastics (1-5 mm) (Lee et al. 2015). The inter- and intra-beach microplastic abundance and distribution were influenced by the direction and transporting energy of winds and currents (Kim et al. 2015a). Accumulation of microplastics in sediments increased the ammonium concentration in the overlying water in laboratory experiments (Cluzaud et al. 2015). Ingested microplastics fibers were found in copepods and euphausiid zooplankton collected from the Northeast Pacific Ocean (Desforges et al. 2015). Pretreatment method was proposed to identify microplastics in fish stomach using Raman spectroscopy, and microplastics were detected in three fish from European seas (Collard et al. 2015). The potential impact of microplastics on zooplankton feeders also was assessed by measuring the ratio by abundance of neustonic microplastics to zooplankton in the Southern Sea of Korea (Kang et al. 2015). More than 200 chemicals were detected in marine plastic debris and their original products, and a comparison of them indicated the leaching or absorption of chemicals from or to plastic debris (Rani et al. 2015). The total unaccounted mass of high- and low-density polyethylene in the marine environment in Korea was estimated at 28 million tons for the period 1995-2012 (Kim et al. 2015b).
These papers substantially increase our understanding about levels of contamination and potential effects on biota. It is clear from this volume and other recent studies (Obbard et al. 2014; Woodall et al. 2014) that some locations and habitats contain substantial accumulations of microplastics; yet estimates of the quantity of plastic debris in the environment indicate that there may still be unreported additional sinks for microplastic debris. Such data are essential to inform risk assessments, because it will facilitate appropriate calculation of encounter rate. We also need to better understand the potential for physical or toxicological harm associated with such encounters. Research in this volume helps to illustrate the complexity of this issue and the challenges in assessing harm. For instance, they are the multiple permutations of size, shape, and potential toxicant burden both by concentration and chemicals and issues associated with interactions among the complex mixtures of chemicals that are found in the environment. Resolving these complex interactions between biological encounter and types of harm will be particularly challenging. Yet, there are indications of substantial accumulation in the environment and based on laboratory studies illustrations of the potential for physical and toxicological harm. Plastics bring many societal benefits, yet nearly all of these can be achieved without the emissions of end-of-life plastic to the ocean. To focus scientific endeavour, it is important to engage with policy makers to identify the key evidence required to move toward solutions that reduce inputs of debris to the oceans. Solutions are known and some would argue that a key challenge is balancing the need for more information about impacts with the need to take action to reduce inputs (Koelmans et al. 2014).

Acknowledgments This study was supported by research projects titled "Environmental Risk Assessment of Microplastics in the Marine Environment" from the Ministry of Oceans and Fisheries, Korea.

\section{Compliance with Ethical Standards}

Conflict of interest The authors declare that they have no conflict of interest.

\section{References}

Andrady AL (2011) Microplastics in the marine environment. Mar Pollut Bull 62:1596-1605

Browne MA, Galloway TS, Thompson RC (2010) Spatial patterns of plastic debris along estuarine shorelines. Environ Sci Technol 44:3404-3409

Browne MA, Niven SJ, Galloway TS, Rowland SJ, Thompson RC (2013) Microplastic moves pollutants and additives to worms, reducing functions linked to health and biodiversity. Current Biol 23:2388-2392 
Carpenter EJ, Smith K (1972) Plastics on the Sargasso Sea surface. Science 175:1240-1241

Carpenter EJ, Anderson SJ, Harvey GR, Miklas HP, Bradford BP (1972) Polystyrene spherules in coastal waters. Science 178: 749-750

Chae DH, Kim IS, Kim SK, Song YK, Shim WJ (2015) Abundance and distribution characteristics of microplastics in surface seawaters of the Incheon/Kyeonggi coastal region. Arch Environ Contam Toxicol (this issue). doi:10.1007/s00244-015-0173-4

Cluzaud M, Kazmiruk M, Kazmiruk V, BendellL (2015) Intertidal concentrations of microplastics and their influence on ammonium cycling as related to the shellfish industry. Arch Environ Contam Toxicol (this issue). doi:10.1007/s00244-015-0156-5

Cole M, Lindeque P, Halsband C, Galloway TS (2011) Microplastics as contaminants in the marine environment: a review. Mar Pollut Bull 62:2588-2597

Collard F, Gilbert B, Eppe G, Parmentier E, Das Krishna (2015) Detection of anthropogenic particles in fish stomachs: an isolation method adapted to identification by Raman spectroscopy. Arch Environ Contam Toxicol (this issue). doi:10. 1007/s00244-015-0221-0

Colton JB, Knapp FD, Burns BR (1974) Plastic particles in surface waters of the Northwestern Atlantic. Science 185:491-497

Cózar A, Sanz-Martín M, Martí E, González-Gordillo JI, Ubeda B, Gálvez JÁ, Irigoien X, Duarte CM (2015) Plastic accumulation in the Mediterranean Sea. PLoS One 10:e0121762

Desforges JP, Galbraith M, Ross PS (2015) Ingestion of microplastics by zooplankton in the Northeast Pacific Ocean. Arch Environ Contam Toxicol (this issue). doi:10.1007/s00244-015-0172-5

Eerkes-Medrano D, Thompson RC, Aldridge DC (2015) Microplastics in freshwater systems: a review of the emerging threats, identification of knowledge gaps and prioritisation of research needs. Water Res 75:63-82

Engler RE (2012) The complex interaction between marine debris and toxic chemicals in the ocean. Environ Sci Technol 46: 12302-12315

Eriksen M, Lebreton LCM, Carson HS, Thiel M, Moore CJ, Borerro JC, Galgani F, Ryan PG, Reisser J (2014) Plastic pollution in the world's oceans: more than 5 trillion plastics pieces weighing over 250,000 tons afloat at sea. PLoS One 9:e111913

Gall SC, Thompson RC (2015) The impact of debris on marine life. Mar Pollut Bull 92:170-179

GESAMP (2015) Sources, fate and effects of microplastics in the marine environment: a global assessment. Kershaw PJ (ed). Rep Stud GESAMP No. 90, 96 pp

Hidalgo-Ruz V, Gutow L, Thompson RC, Thiel M (2012) Microplastics in the marine environment: a review of the methods used for identification and quantification. Environ Sci Technol 46: 3060-3075

Jambeck JR, Geyer R, Wilcox C, Siegler TR, Perryman M, Andrady A, Narayan R, Law KL (2015) Marine pollution. Plastic waste inputs from land into the ocean. Science 347:768-771

Kang JH, Kwon OY, Shim WJ (2015) Potential threat of microplastics to zooplanktivores in the surface waters of the southern sea of Korea. Arch Environ Contam Toxicol (this issue). doi:10. 1007/s00244-015-0210-3

Kim IS, Chae D.H, Kim SK, Choi SB, Woo SB (2015a) Factors influencing the spatial variation of microplastics on high-tidal coastal beaches in Korea. Arch Environ Contam Toxicol (this issue). doi:10.1007/s00244-015-0155-6

Kim M, Hyun S, Kwon JH (2015b) Estimation of the environmental load of high- and low-density polyethylene from SouthKorea using a mass balance approach. Arch Environ Contam Toxicol (this issue). doi:10.1007/s00244-015-0192-1
Koelmans AA, Gouin T, Thompson RC, Wallace N, Arthur C (2014) Plastics in the marine environment. Environ Toxicol Chem 33:5-10

Law KL, Thompson RC (2014) Microplastics in the seas. Science 345:144-145

Lee KW, Shim WJ, Kwon OY, Kang JH (2013) Size-dependent effects of micro polystyrene particles in the marine copepod Tigriopus japonicus. Environ Sci Technol 47:11278-11283

Lee J, Lee JS, Jang YC, Hong SY, Shim WJ, Song YK, Hong SH, Jang M, Han GM, Dang DS, Hong S (2015) Distribution and size relationships of plastic marine debris on beaches in SouthKorea. Arch Environ Contam Toxicol (this issue). doi:10.1007/s00244015-0208-x

Lithner D, Larsson A, Dave G (2011) Environmental and health hazard ranking and assessment of plastic polymers based on chemical composition. Sci Total Environ 409:3309-3324

Obbard RW, Sadri S, QiWong Y, Khitun AA, Baker I, Thompson RC (2014) Global warming releases microplastic legacy frozen in Arctic Sea ice. Earth's Future 2:315-320

Plastic Europe (2015) Plastics - the Facts 2014/2015 An analysis of European plastics production, demand and waste data. Plastic Europe, Brussels

Rani M, Shim WJ, Han GM, Jang M, Song YK, Hong SH (2015) Qualitative analysis of additives in plastic marine debris and its new products. Arch Environ Contam Toxicol (this issue). doi:10. 1007/s00244-015-0219-7

Rochman CM, Hoh E, Kurobe T, Teh SJ (2013) Ingested plastic transfers hazardous chemicals to fish and induces hepatic stress. Sci Rep 3:3263

Ryan PG, Moloney CL (1990) Plastic and other artifacts on SouthAfrican beaches: temporal trends in abundance and composition. South African J Sci 86:450-452

Seltenrich N (2015) New link in the marine food chain? Marine plastic pollution and seafood safety. Environ Health Persp 123:A34-A41

Song YK, Hong SH, Jang M, Kang JH, Kwon OY, Han GM, Shim WJ (2014) Large accumulation of micro-sized synthetic polymer particles in the sea surface microlayer. Environ Sci Technol 48:9014-9021

Song YK, Hong SH, Jang M, Han GM, Shim WJ (2015) Occurrence and distribution of microplastics in sea surface microlayer in Jinhae Bay, South Korea. Arch Environ Contam Toxicol (this issue). doi:10.1007/s00244-015-0209-9

Syberg K, Khan FR, Selck H, Palmqvist A, Banta GT, Daley J, Sano L, Duhaime MB (2015) Microplastics: addressing ecological risk through lessons learned. Environ Toxicol Chem 34:945-953

Thompson RC, Olsen Y, Mitchell RP, Davis A, Rowland SJ, John AWG, McGonigle D, Russell AE (2004) Lost at sea: where is all the plastic? Science 304:838

Thompson RC, Swan SH, Moore CJ, von Saal FS (2009) Our plastic age. Phil Trans R Soc B 364:1973-1976

Van Cauwenberghe L, Devriese L, Galgani F, Robbens J, Janssen CR (2015) Microplastics in sediments: a review of techniques, occurrence and effects. Mar Environ Res. doi:10.1016/j.mar envres.2015.06.007

Woodall LC, Sanchez-Vidal A, Canals M, Paterson GLJ, Coppock R, Sleight V, Calafat A, Rogers AD, Narayanaswamy BE, Thompson RC (2014) The deep sea is a major sink for microplastic debris. Royal Soc Open Sci 1:140317

Wright SL, Rowe D, Thompson RC, Galloway TS (2013a) Microplastic ingestion decreases energy reserves in marine worms. Curr Biol 23:1031-1033

Wright SL, Thompson RC, Galloway TS (2013b) The physical impacts of microplastics on marine organisms: a review. Environ Pollut 178:483-492 